UNIVERSITY OF GOTHENBURG

SCHOOL OF BUSINESS, ECONOMICS AND LAW

WORKING PAPERS IN ECONOMICS

No 441

\title{
Renewable Energy Expansion and the Value of Balance Regulation Power
}

Finn Försund and Lennart Hjalmarsson

April 2010

ISSN 1403-2473 (print)

ISSN 1403-2465 (online)

Department of Economics

School of Business, Economics and Law at University of Gothenburg

Vasagatan 1, PO Box 640, SE 40530 Göteborg, Sweden

+46 31786 0000, +46317861326 (fax)

www.handels.gu.se info@handels.gu.se 


\title{
RENEWABLE ENERGY EXPANSION AND THE VALUE OF BALANCE REGULATION POWER*
}

by

\author{
Finn R. Førsund, \\ University of Oslo \\ Lennart Hjalmarsson, \\ University of Gothenburg
}

March 25, 2010

\begin{abstract}
To achieve a stable and reliable electricity supply, efficient provision of reserve capacity or, more generally, ancillary services is crucial. Because of the expansion of wind power with random variation in supply, and expected environmental restrictions in hydropower operation causing reductions in regulated hydropower capacity, the balancing power and system reliability issues have become topical in Scandinavia. Moreover, there seems to be a widespread opinion that increase in wind-power generation will lead to increased demand for regulating power, much higher prices for reserves and a much higher value of regulated hydro power. Thus, this chapter deals with the value of balance regulation power, or electricity reserves, in the Nordic electricity market, and we will address the issue of the future value of electricity reserves, hydro capacity in particular, that could be used either for energy production or to balance power production, and more generally discuss the value of balancing power in the Nordic electricity system. In the first, theoretical, part of this study we will apply a simple dynamic electricity generation model, involving hydropower, thermal power and wind power to derive the value of the water in a dam of a hydropower plant. In the second, more empirically oriented, part we will address a number of issues related to balance regulation and the value of balancing power with focus on the Nordic electricity market and against the background of an expanding generation capacity of intermittent renewable electricity, especially wind power.
\end{abstract}

JEL Classification: Q4, Q51, L94

Keywords: Electricity, ancillary services, reserve capacity, regulating power, wind power

\footnotetext{
* The research presented in this paper was carried out as a part of the R\&D programme "Hydropower Environmental impacts, mitigation measures and costs in regulated waters". It has been established and financed by Elforsk, the Swedish Energy Agency, the National Board of Fisheries and the Swedish Environmental Protection Agency. www.vattenkraftmiljo.nu
} 


\section{Introduction}

To achieve a stable and reliable electricity supply, efficient provision of reserve capacity or, more generally, ancillary services is crucial. Because of the expansion of wind power with random variation in supply, and expected environmental restrictions in hydropower operation causing reductions in regulated hydropower capacity, the balancing power and system reliability issues have become topical in Scandinavia. While system reliability is less of a problem in a regulated electricity market, the efficient design of markets for ancillary services in liberalised electricity markets is more of a challenge. Moreover, in the integrated (DanishFinnish-Norwegian-Swedish) Nordic electricity market with country-specific Transmission System Operators (TSOs) or Independent System Operators (ISOs), the harmonisation of balance regulation is another challenge. A third challenge is harmonisation of terminology, which greatly varies across systems and countries, including across the Nordic countries. There are several kinds of ancillary services, and one may distinguish among:

- Frequency controlled (automatic reserves)

- Fast (manually controlled) reserves, in thermal system called spinning reserves for rampable thermal units already on-line and non-spinning reserves for off-line units such as gas turbines or interruptible or curtailable loads

- Replacement or peak-load reserves (thermal plants that may take hours to activate)

- Voltage support (services, often provided by equipment such as shunt capacitors, static var compensators, and synchronous condensers that are required to maintain voltage stability)

- Black-start capability (generating units that self-start without an external source of electricity, thereby restoring power following system blackouts)

Here we will focus on the first three types of services, and especially the first two. These are the services the TSOs buy to maintain reliability of supply. They are listed according to their 'quality' - the speed at which they can provide their services. Higher quality services are substitutes for lower quality services but not vice versa, so there is a certain degree of product differentiation in ancillary services. 
Thus, this chapter deals with the value of balance regulation power, or electricity reserves, in the Nordic electricity market against the background of an expanding generation capacity of renewable electricity, especially wind power, and expected environmental restrictions in hydropower operation causing reductions in regulated hydropower capacity. We will therefore address the issue of the future value of electricity reserves, hydro capacity in particular, that could be used either for energy production or to balance power production, and more generally discuss the value of balancing power in the Nordic electricity system.

In the first part of this study we will clarify how to calculate the value of the water in a dam of a hydropower plant when the alternative is to cease operating the dam due to restoration of the natural river flow. From a market point of view this issue concerns optimal pricing of hydropower reservoirs in a competitive market. The foundation of socially optimal prices in the wholesale electricity market is studied using a simple but comprehensive dynamic model involving hydropower, thermal power (consisting of nuclear and conventional thermal) and wind power. Key qualitative features of the price formation will be discussed using specially developed figures. A special emphasis is put on discussing the influence of introducing more wind power on the value of hydropower.

As a general setting for our analysis, we will look at the electricity-generating sector of a (Scandinavian-like) country (may also be a group of cooperating countries like Nord Pool) having as generating technologies hydropower with reservoirs, conventional thermal capacity (coal-fired), nuclear power stations, and wind power and run-by-the-river power plants without significant water storage possibilities within the time unit that will be considered. Each technology is represented as an aggregate sector. The capacities and production of hydropower stations are simply added together, as are inflows and reservoirs. According to Hveding's conjecture; see Hveding (1968) and Førsund (2007), this procedure will give a consistent picture of the hydropower sector (provided some assumptions are fulfilled). The capacities of the thermal sectors are assumed to be uniquely aggregated according to the merit-order principle. For simplicity, we assume that there is no trade with the outside world; (for trade between countries with different generating technologies, see Førsund (2009)).

Hydropower serves two regulating needs: (1) regulating the supply of energy over the yearly cycle of low demand in the summer season and high demand in the winter season, as in the Nordic countries, and (2) serving as the most flexible balancing power in real time. The need 
for balancing power arises from the practical impossibility of having a market for electricity in real time. A standard market organisation for electricity is to have a day-ahead spot market. Deviations between planned supply and demand in real time must then be covered by balancing power. Thus, the fundamental reason for having a balancing market is uncertainty about supply and demand. However, a study of the longer-term regulation over seasons may be done instructively enough without bringing in uncertainty. This is the approach taken in Section 2. The balancing market is discussed in Section 3. In this, more empirically oriented, section we will address a number of issues related to balance regulation and the value of balancing power with focus on the Nordic electricity market and against the background of an expanding generation capacity of renewable electricity, especially wind power. First we present the organisation of balance regulation in the Nordic market, followed by a discussion in Section 3.2 about the value of regulating power in a competitive market and especially the link or arbitrage opportunities between the spot market and the regulation market. Finally, the impact on the value of balancing power in the Nordic system from a substantial expansion of wind power is discussed in Section 3.3. Section 4 concludes the paper.

\section{Optimal pricing of hydropower reservoirs}

The purpose of this section is to bring out the nature of socially optimal pricing rules. Such pricing rules serve as benchmarks when evaluating actual pricing of electricity and the value of hydropower reservoirs. It should be recognised that the actual prices may not reflect the socially optimal prices, especially in the case of market power or price regulation. Thus, this section provides the theoretical underpinnings for the more empirically oriented discussion of balance regulation in Section 3.

\subsection{General principles}

The following four types of generation technologies are relevant for the analysis:

i) Hydro

ii) Two types of thermal: conventional (gas, coal, oil, combined heat and power) and nuclear

iii) Wind 
There are also hydropower resources that have no or very limited storage capacity of water; i.e. run-of-the-river power. This kind of power is also of an intermittent nature. From a modelling point of view, it can be aggregated together with wind power. For ease of exposition, we will refer to intermittent power as wind power. There is full certainty about the wind-power production profile, the inflow to the reservoirs and the period demand functions. The generation of electricity is viewed as one aggregate system for each of the technologies.

Hydro and wind generation are assumed to have zero marginal cost; all current costs are fixed costs that depend on non-negative production (this is quite a realistic assumption). The fixed costs are neglected in the analysis since we are not looking at new investments, but only at the problem of optimal management of existing capacities.

Thermal generations have current primary fuel costs that depend on the output levels. The fixed cost part is not included in the cost function. The cost functions are constructed as merit-order functions. It is assumed that we have unique rankings, but this is not necessarily the case in real applications; see Førsund (2007). The outputs of the thermal sectors are constrained.

We are only looking at the problem of managing available generation capacities. New investments will not be considered. The social planner maximises consumer plus producer surplus using demand functions for electricity for each period, and the cost functions for thermal capacity distinguish between nuclear and conventional capacity. This is a common procedure for studying the electricity sector, but implies that we are using a partial model without feedback links to the rest of the economy.

The management problem when hydropower with reservoirs is involved is always a dynamic problem; the water used today can alternatively be used tomorrow. We therefore have to consider a dynamic setting comprising a certain number of future periods. We will regard managing the other generating technologies as static problems. However, starting up and closing down both conventional and nuclear power also involves dynamics. Yet, since these types of dynamics are short-run and quite different from the long-run dynamics of hydropower, we will neglect them. The complete model is set out in Appendix. We are only looking for qualitative features of optimal solutions. We will present typical feasible cases that are consistent with optimal solutions. Discrete time is considered, and the period length 
may be chosen from one hour, one day, one week, one month or one season within a year depending on the focus of the analysis. Energy (kWh) will be used as the key variable, and capacity (kW) will not be used explicitly. If no specific time profile for capacity is entered, then an even profile based on a constant capacity within each period is assumed.

A special feature of the solution to the optimisation problem is that the solution is recursive in the sense that there are only explicit links between conditions for a period and the next period. We can therefore illustrate the qualitative nature of the solution with figures based on two periods. Of course, a simultaneous solution for all periods is required. We will first simplify further and provide illustrations based on only two periods within the planning horizon, but will comment upon generalisations to more periods. Two periods may correspond to an analysis of the basic transfer of water from high-inflow periods with relatively low demand to low-inflow periods with relatively high demand, i.e. in Scandinavia the summer and winter seasons, respectively. It is typical to run down the reservoirs during the winter and start refilling them again when the snow melts in the spring and summer.

A general result for optimal pricing in a pure hydro model is that prices only change when constraint becomes binding (Hveding, 1968). We will study how this rule is affected by the existence of additional different generating technologies.

In Figure 1, we have placed a "bathtub" showing the hydropower resources for the two periods. The bathtub is indicated by the bottom line from A to D, and by walls erected from these points. Period 1 is measured along the left-hand wall of the bathtub, and period 2 along the right-hand wall. The water resource available for period 1, made up of water inherited from the period before period 1 in the general case and the inflow during period 1, is AC, and the inflow in period 2 is CD. ${ }^{1}$ All available water is to be used up within the two periods. (In the general case we would consider how much water we should save in period 2 for the next period.) The storage capacity for water is given by BC, and the walls erected from these two points illustrate the reservoir capacity. For period 1, the production possibilities are extended to the left of the wall of the hydro bathtub, indicated with marginal cost curves for wind

\footnotetext{
${ }^{1}$ Although we refer to the hydro resource as water, we measure the hydro bathtub in energy units, e.g. kWh. Specific characteristics such as the height of head and the efficiency of transforming water to electricity are taken into consideration.
} 
energy, following the floor of the extended bathtub since the variable cost is zero, anchored at the left-hand hydro bathtub wall, and then comes, in merit order, the marginal cost curve for

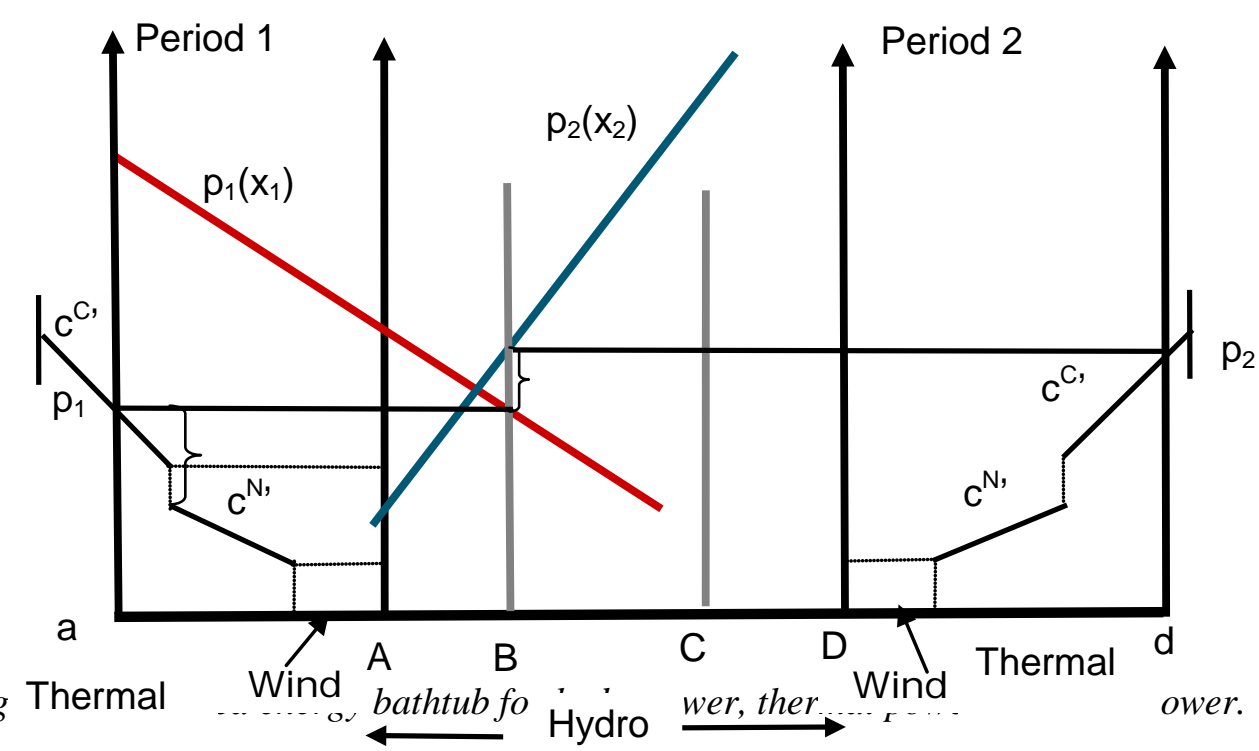

nuclear capacities $\left(c^{N}\right)$ and lastly the marginal cost curve for conventional thermal capacities $\left(c^{C}\right)$. The short vertical line indicates the given capacity limit of thermal. The cost curves are for simplicity made linear in the figure (they could be made as step curves, as is common in applied studies). The marginal cost curves have standard slopes of increasing marginal cost. We have assumed that nuclear power has lower marginal cost than conventional thermal, and that the latter has a steeper marginal cost curve. There is a jump from the most expensive nuclear capacity to the cheapest conventional thermal capacity. Now, the extension of the hydro bathtub for period 2 on the right-hand side is a mirror image of the marginal cost curves for period 1 . There are no changes in primary energy prices between the periods and no technical change. We have assumed that the same expected amount of wind power is available in both periods.

The demand curve for electricity for period 1 is anchored on the left-hand energy wall erected from point $\mathrm{A}$, and electricity consumption is measured from left to right. The demand curve for period 2 is anchored on the right-hand energy wall (the anchoring is not shown explicitly) erected from point $\mathrm{D}$ and electricity consumption is measured from right to left. Both demand curves are drawn linear for ease of illustration. Period 1 is a low-demand period while period 2 is a high-demand period. 
The optimal solution to the management problem implies that the placement of the outer walls of the extended energy bathtub is endogenously determined; see Førsund (2007). For ease of exposition, we erect the two walls such that we get illustrations consistent with an optimal underlying model solution (Appendix) of a nature we want to discuss. The equilibrium price for period 1 implies use of all three technologies in period 1 . Conventional thermal is the marginal technology in the sense that total capacity is partially utilised and nuclear and wind are fully utilised. Had the equilibrium price been lower than the lowest marginal cost of thermal, indicated by the relevant thin dotted horizontal line, then no conventional thermal would have been utilised. Had the price been lower than the lowest marginal cost of nuclear power, indicated by the horizontal thin dotted line at the start of the marginal cost curve, then only wind and water would have been used. The shadow price of an increase in nuclear capacity is the vertical distance from the full capacity point to the price line, and the marginal value of more wind power is the full price. The hydro contribution is the amount of water, $\mathrm{AB}$, locked in to be used in period 1 and a full reservoir $\mathrm{BC}$ is left for period 2. The water value for period 1 is equal to the price. It is a general result that the water value in a period is equal to the marginal cost of the partially utilised technology.

In period 2 the wind resource is the same and the demand is such that thermal capacity is partially utilised. The full water reservoir from period 1, BC, plus the inflow in period 2, CD, hence $\mathrm{BD}$, is used in period 2. The result for prices is that the high-demand period has a higher price than the low-demand period. Both hydro and thermal are used as peak load capacity. The qualitative result for the pure hydro case is repeated with additional generating capacities of other technologies.

With more than two periods, all water will generally not be used up in a period that is not the last. When considering a general solution, we start from the last period and move towards the first period, following the backward solution principle of Bellman (1957). All available water will then only be used up in an intermediate period if the optimal price in the next period is lower than the price resulting from full utilisation of the water in the current period.

We also have to assume that there is enough production (and transmission) capacity to process all available water in a period. However, there may be restrictions on the turbine capacities (and transmission capacities) which could make processing of all available water 
unfeasible. Restrictions on hydro generating capacity can be introduced straightforwardly; see Førsund (2007). The general effect is that the price in the period with a binding production restriction will be higher than without such a restriction, and in the multi-period case more water has to be transferred to the period after the period with the production capacity constraint.

To study the effect of varying wind resource, we have in Figure 2 assumed that the maximal

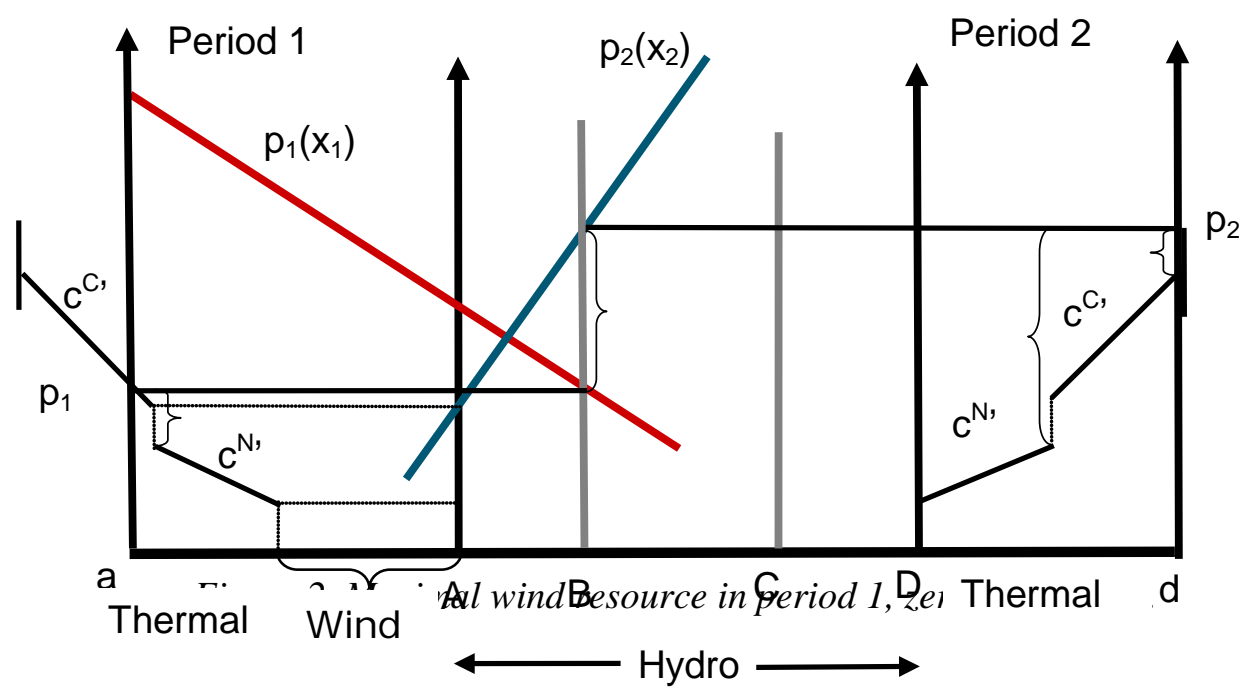

wind output is available in period 1 and that no wind power is available in the high-demand period, keeping the same hydropower bathtub and the same demand curves. The nuclear marginal cost curve for period 2 is anchored on the hydro bathtub wall for period 2 and extends to the right. The increase in the wind resource in period 1 leads to a lower price, because the use of hydro is not changed in this example, but the price in period 2 is now considerably higher than the optimal price in period 1. Hence, it is socially advantageous to transfer a full reservoir from period 1 to period 2. All available capacities are utilised, creating a price that is higher than the highest marginal cost of the thermal capacity. There is a positive shadow price on the thermal capacity. The shadow price on nuclear capacity is the vertical distance from the full capacity point on the marginal cost curve up to the price line, and it is now considerably higher than with an even distribution of wind power between the periods. The lower price in period 1 implies that a smaller share of thermal capacity is utilised. The general result is that the more uneven the wind resource is over the periods, the more uneven the period prices, and vice versa. 
When the wind disappears in a period, the shortfall will be taken up to some extent by the other technologies provided capacities are available. The demand will also be influenced by the shortfall via a higher price. It is interesting to see that the strain on hydropower is the same in the two situations illustrated in Figures 1 and 2 for quite different levels of wind power.

A typical optimal solution in the pure hydro case will be that the price is the same in both periods. This may still be a typical situation, and is illustrated in Figure 3. Now there is no

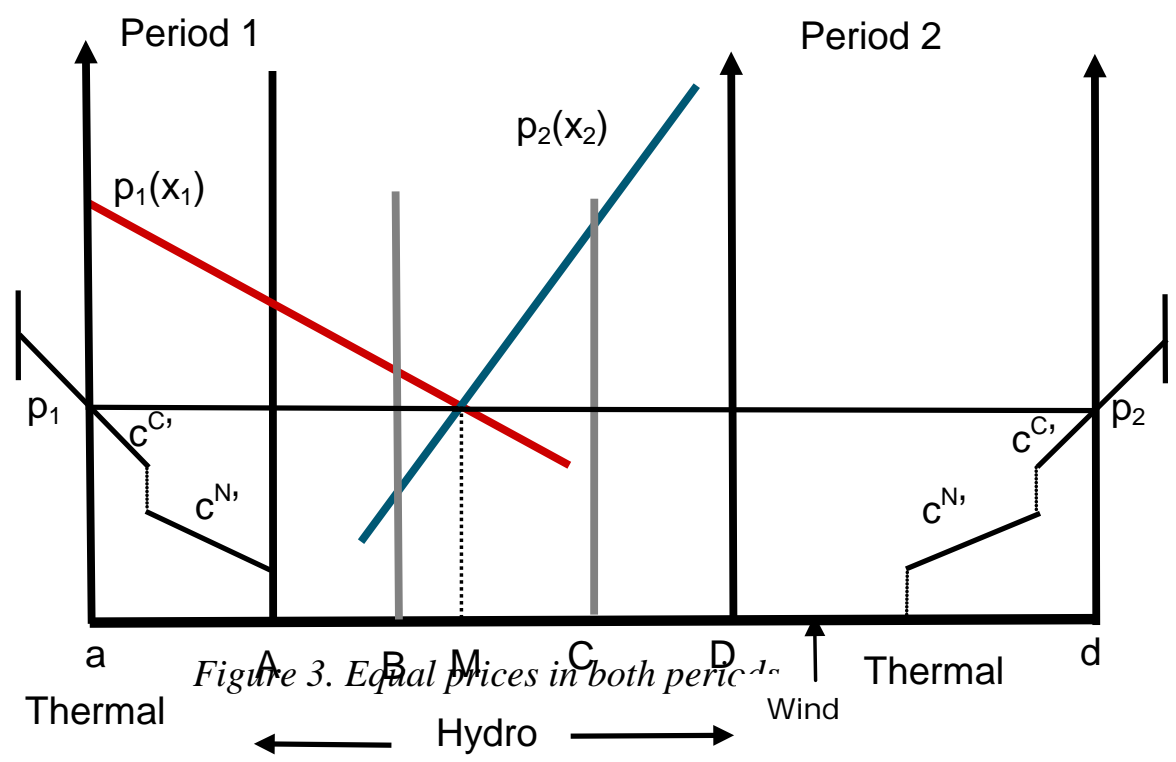

wind resource in period 1 , but a maximal availability in period 2 . The illustration shows that enough generating capacity is available in period 2 to equalise prices within the capacity limit of the conventional thermal capacity. Enough water, MC, is transferred to period 2 to keep the same price and to benefit from the wind resource. An obvious consequence of equal price is that the same amount of the partially utilised technology will be used in each period. Water and wind take care of the peak load in period 2. This may be a general feature also with a mix of technologies, provided that the hydropower has a certain market share. We may have many periods with the same price both before and after a period with a price change.

If the wind resource is at its maximum, it may be the case that no hydro resource will be used in that period. The condition is that no water is locked in, i.e. there must be enough storage capacity in the period to store all available water in the period and transfer it to the next period. The finer the time period resolution, the more relevant this condition becomes. 
Figure 4 illustrates such a case.

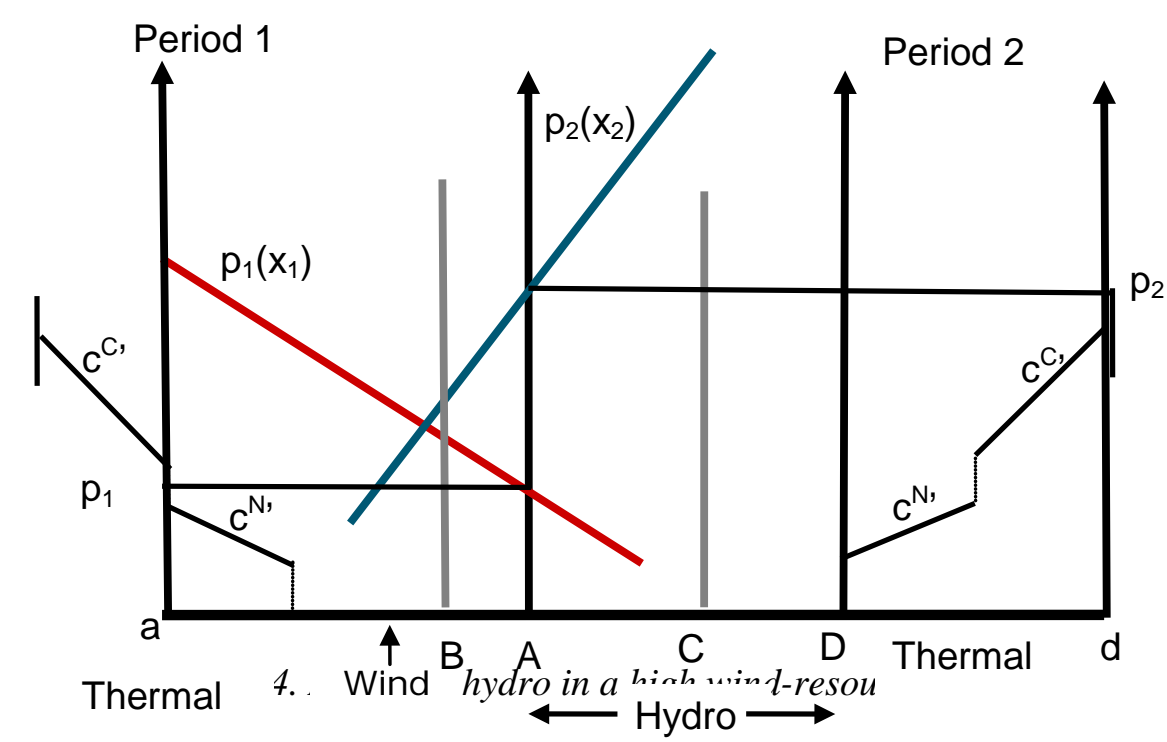

We may think of period 1 as nighttime and period 2 as the following daytime. The relative availability of capacities has now been changed from the previous figures. The available water in period 1 is AC and the size of the reservoir is still measured by BC, but the storage is now greater than the available water, and the vertical line marking the left wall of the reservoir erected from B is now to the left of the hydro bathtub wall erected from A.

The optimal price in period 1 implies that only nuclear and wind capacity are used while both conventional thermal and hydro remain unused. In the high-demand period 2, all the water is now used in addition to constraining the thermal capacities. The pattern of use of the hydro capacity changes maximally from zero to processing all available water. In a situation illustrated in period 1 with available reservoir capacity, it might be socially profitable to run pumped-storage capacity. Pumped storage increases the amount of stored water over a yearly period, and hence increases the flexibility of hydropower. The necessary condition for usingsuch capacity is that the income on a unit of water in period 2 pumped up in period 1 is greater than the cost of pumping up the water, assuming that more electricity has to be used to pump up a unit of water than generated by the same amount in period 2. In addition, when considering an investment project there are fixed costs, especially capital costs. 
In Figure 4 all the water in period 2 is again used up in that period. We will try to indicate more explicitly how a two-period window may function within a general solution for many periods. Figure 5 illustrates the two periods $t$ and $t+1$, and we have entered the optimal

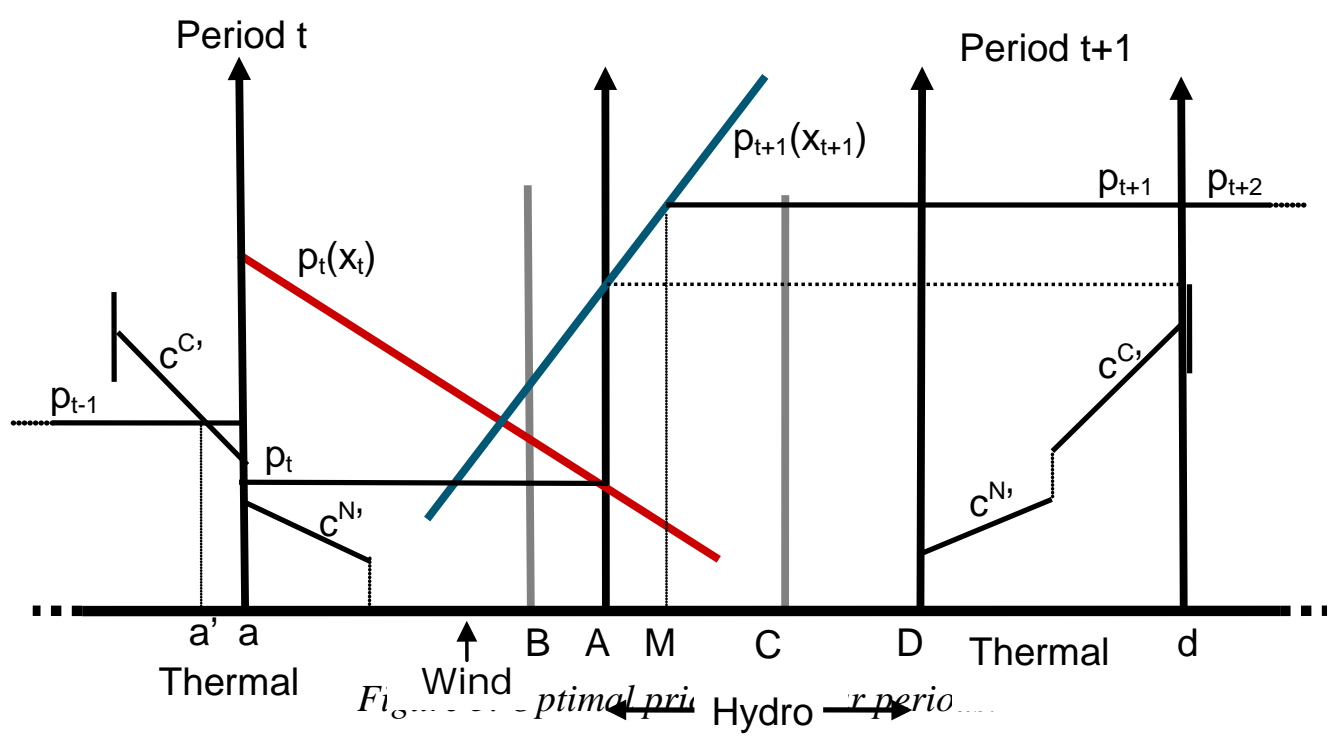

prices for period $t-1$ and period $t+2$. The price in period $t$ is kept at the same level as the price in period 1 in Figure 4. No use of hydropower may extend for more than one period. The price in period $t-1$ is lower than the price in period $t+1$, implying that no water is used in period $t-1$, because the water values for period $t-1$ and $t$ must be equal when no hydro-related constraint is binding (see Appendix, equation A5). However, the price in period $t$-1 is higher than the price in period $t$, implying that more thermal capacity is used. This may be due to less wind resource, or higher demand, or both. The increase in active thermal capacity is a'a. (Note that we do not have to illustrate the price formation in period $t-1$ to derive this result, it follows directly from the price level chosen.) The price in period $t+1$ is higher than the price in period 2 in Figure 4, indicated by the thin broken horizontal line. The price in period $t+1$ is equal to the price in period $t+2$ (this is how backward induction works), implying that not all available water in period $t+1$ is used but the amount AM is transferred to period $t+2$. When water is actually used the water values in periods $t-1, t, t+1$ and $t+2$ are all equal and equal to the prices in periods $t+1$ and $t+2$. The shadow price on the thermal capacity limit has increased compared with the situation illustrated in Figure 4.

\subsection{The value of hydropower when wind power expands}


A national hydropower sector has many individual hydro plants with reservoirs. If we consider a marginal plant, i.e. a plant that will not influence prices if its production varies or should even fall to zero, then the income of a plant over a yearly cycle depends on the prices at which the plant sells. The benchmark will be the optimal utilisation profile of a plant, i.e. selling electricity such that profit is maximal to the social prices prevailing over the year. The maximal income is generated by a plant that manages to sell all its output at the maximal price. However, this will not be the average case, but will rather be possible for only a few plants, if any.

If we consider a certain level of wind power capacity, a way of seeing the consequences for the value of hydropower, using the illustrations above, is to use the expected wind energy for each period as in Figure 1. Then moving to the extreme situation with maximal wind in one period and zero in the other as in Figure 2, we see that the minimum price has decreased and the maximal price has increased. In the figures, the same amount of hydropower is produced in each period with considerably less production in the low-price period. Therefore, the income increases for hydropower with an uneven wind profile.

The ability to store water implies that it is optimal to use water in the highest price periods to bring down the prices and create greater social surplus. Periods with high wind power may even imply that no hydropower is used at all. The pricing in such periods is then determined the standard way i.e. by equating demand and current supply from the other technologies. Prices may then vary with demand. If sufficient wind power becomes available in a period, it may even be optimal to shut down nuclear power completely. This will occur if the period price becomes lower than the lowest nuclear marginal cost indicated by the relevant thin horizontal line in Figure 2. However, the closing and start-up cost of a nuclear plant may exceed the revenue from running the windmill if the maximal wind condition does not last long enough, and if this is the case it does not pay to utilise the wind power, but instead just let it go (like spilling water from a hydro plant).

When the period length is short, an hour or nighttime/daytime, then saving maximal water for high-price periods may be optimal, as illustrated in Figures 4 and 5 . The latter figure illustrates how the two-period window may work within a general solution for the complete 
planning period. The situation with zero use of water in low-price periods will increase the value of hydropower ceteris paribus. However, since more water is transferred to use in the high-price periods, the prices in such periods may decrease. But we also have the complication that if the wind fails in high-demand periods, the price may go up. The choice of the benchmark situation may then be crucial for our evaluation of price levels. It is therefore not obvious to predict the outcome for the value of hydropower without an empirical model.

\section{Future development of wind power}

There are ambitious plans in many countries to expand renewable energy and especially wind power substantially over the next 10-20 years. The EU 20 per cent renewable energy target for 2020 is a very important driving force. Intermittent power technologies like wind and solar power create new challenges for power system regulation.

The utilisation pattern of the intermittent technologies and consequences for socially optimal prices may be analysed in our type of model by using the above figures. If we for simplicity keep hydro and thermal capacities constant and only expand wind capacity, a later year with increased wind capacity can be illustrated by expanding the potential maximal outer walls of the energy bathtubs. The maximal wind occurrence will increase while the minimum stays, of course, at zero. If the distribution of wind over the same number of periods within e.g. a year is stretched at the modal value, then there will be more periods with wind power availability above a certain level. If the wind conditions become more different when the capacity expands, the episodes with zero wind may actually decrease in number, e.g. due to a greater geographical spread of windmills with different wind conditions in the same period. The number of periods with down-regulation of hydropower will increase, and so will the volume of down-regulation. At the other end we have that more water has to be used when the wind is down in high-demand periods, and because the number of such episodes may increase, there is an extra strain on the hydro resources. The price swings across periods will therefore become more volatile and show larger differences.

In Nord Pool Denmark has the largest share of wind power, around $20 \%$ of annual generation, while the share of wind power in the other countries is still negligible. The share of hydro power is largest in Norway, close to $100 \%$, while it is almost zero in Denmark. Finland and Sweden are in between with hydro shares of about $20 \%$ and $45 \%$ respectively. 
Although there is a rather large transmission capacity between the Nordic countries and between Nord Pool and Northern Europe, there is substantial variation in area prices across the Nordic countries with much higher spot-price volatility in Denmark and very low volatility in the southern part of Norway, here illustrated by the Oslo area; See Figure 6 for spot price volatility between 2001 and February 2010. The sequence in Figure 6 is from most volatile to least volatile price area.

East-Denmark and West-Denmark have much more volatile prices than the Oslo area with Sweden and Finland in between. On the other hand the (un-weighted) average spot price for the entire period, 2001-February 2010, varied very little across countries, from €32,8/MWh in Sweden to 32,1 in Oslo for all these areas except West-Denmark with an average spot price of €30,3/MWh. In Section 3.3 we will provide more information on volatility.

Since the expansion of wind power is not derived from consumers' willingness-to-pay, increased wind power capacity may easily lead to more production than matched by the increase in demand over time. Unless export possibilities out of Nord Pool are expanded by investing in interconnectors to continental Europe or England, this will lead to a lower average price, and the average value of hydropower will consequently fall.

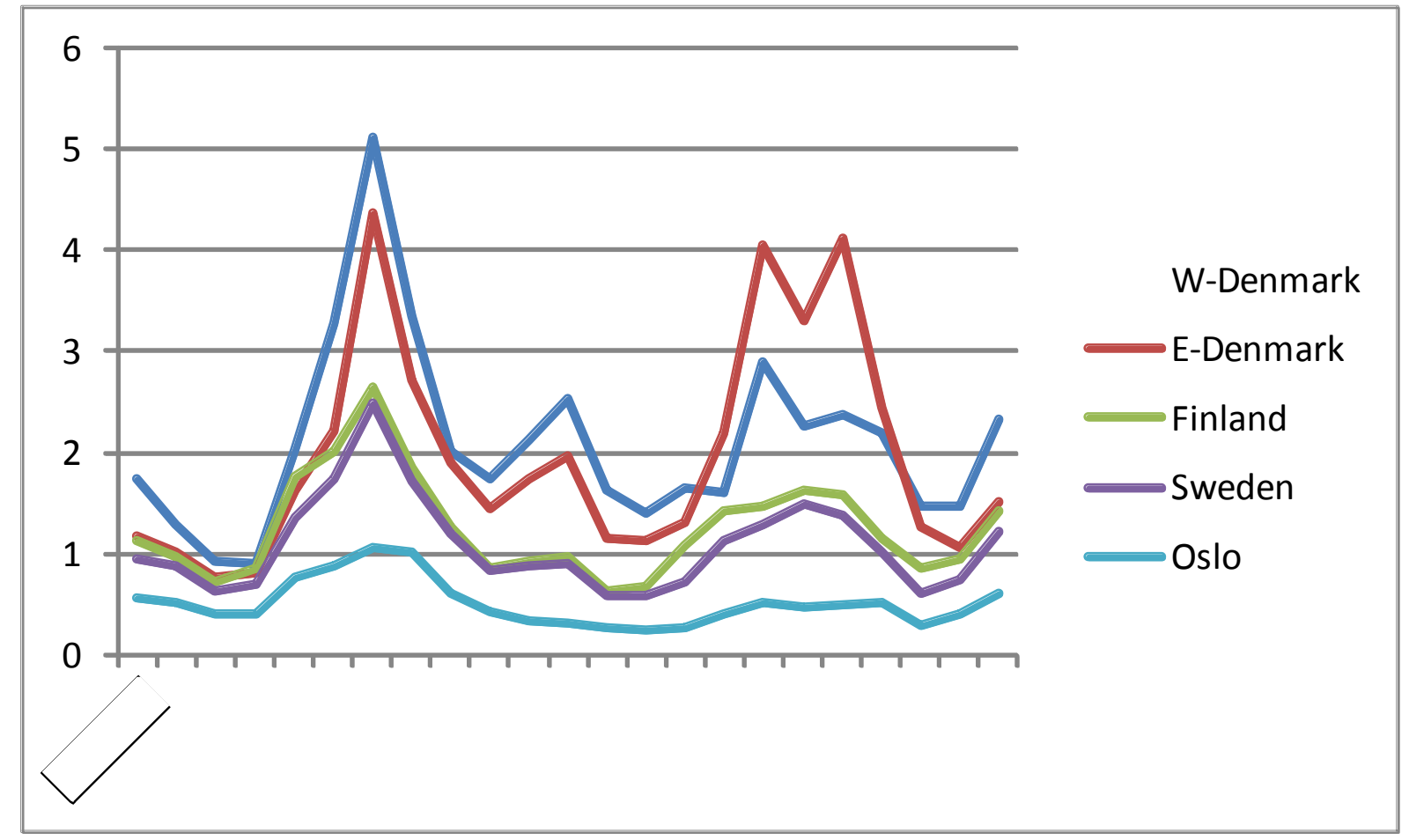


Figure 6. Spot price volatility measured as standard deviation for consecutive hours during the day.

The consequences of increased demand inside the region may be studied in Figure 1-5 above by shifting the demand curves upward. The general and rather obvious result is increased prices in both periods, and this result is easily generalised to more periods, implying a lower higher price also for hydropower.

\section{The role of uncertainty}

For long-term management of hydro reservoirs uncertainty about inflows will play a distinct role for the price formation in the pure hydro case. It will be optimal to process less water when inflows fall short of expectations, resulting in an optimal price increase, and vice versa if inflows are above expectations; see Førsund (2007). When considering that also the wind resource is stochastic, the analysis becomes quite involved and is beyond the modelling attempt here. But a conjecture is that the optimal strategy for a manager is to react to wind variability in the same way as to inflow variability. This means that a lower wind than predicted should lead to a reaction on the hydropower side similar to the reaction to less inflow than predicted; less water should be processed and hence the price should increase. The higher the share of wind power, the greater the necessary reaction on the water side. But a crucial question is whether there is any correlation between wind availability and water inflows. If not, then the rule above for how to react to wind variation is valid, but if there is a correlation, it must be taken into consideration and may either strengthen or weaken the price variation, depending on the sign of the correlation. This issue does not seem to have been researched yet.

The treatment of uncertainty may be especially crucial for high-demand periods and low reservoir levels. If the wind resource disappears in such a situation, the price may become a price spike of considerable magnitude. To avoid such price episodes, it may be optimal to keep more water in the reservoirs to face such contingencies due to the stochastic nature of the wind. However, it is costly to the society to keep such reserves, and individual hydro generators cannot be expected to keep such reserves unless they are paid for this in excess of the current spot price. This is the same situation as paying for stand-by thermal capacity. 
Wind may disappear quite suddenly, so it is also a question of having more power capacity in reserve. It does not help to have enough energy in the form of stored water if that water cannot be processed instantly in sufficient quantities. Thus, the reserve issue created by the stochastic wind concerns both energy and power capacity.

\section{Markets for balance regulation}

The purpose of this section is to address a number of issues related to balance regulation with focus on the Nordic electricity market. First we present the structure and design of the Nordic balance regulation, and then we address the value of regulating power in a competitive market and especially the link or arbitrage opportunities between the spot market and the regulation market. Finally, we discuss the impact on the value of balancing power in the Nordic system from a substantial expansion of wind power. 


\subsection{The structure and design of the Nordic balance regulation}

The Nordic electricity market is divided into two balancing systems: the synchronous part of Nordel and Western Denmark, respectively. Western Denmark belongs to the UCTE and with Energinet.dk as TSO for this area in relation to the UCTE system. Here we will focus on the synchronous part of Nordel, where frequency should be kept within the range of 49.9-50.1 Hz. In this system the Swedish TSO, Svenska Kraftnät, and the Norwegian TSO, Statnett, have a joint frequency-maintenance responsibility with access to balancing power from a common Nordic list of resources. The regulation resources from Denmark and Finland are coordinated by Energinet.dk and the Finnish TSO, Fingrid, respectively.

The balance regulation is a relatively decentralised process with a sort of step-wise convergence from the spot market to the real-time operation. All market agents are so-called balance responsible parties, BRPs, with an obligation (and strong incentives) to balance their

supply and demand on an hourly basis; hence the settlement period is an hour of the trading day. The spot market is an hourly day-ahead market starting at midnight and lasting for 24 hours. The first, ex ante, balance for the next 24 hours is provided by the closing of the bids to the day-ahead spot market at 12:00 (noon) and the plans sent to the TSOs. After that, any deviations between planned and actual supply and demand can be settled by trading in the hour-ahead Elbas market, by revising existing production or consumption plans or through bilateral trade, until the hour of real-time operation.

For a day-ahead spot market of the Nordic kind, which closes 12 hours before real-time operation starts, there is substantial uncertainty about demand and supply conditions, although part of this uncertainty is resolved by the Elbas market and other adjustments of production plans. However, with this type of market design, a clear separation between market (Nord Pool) and regulation (TSOs), there is a need for a regulating power market due to the uncertainty regarding:

- Demand (temperature, special events, etc.)

- Supply disruptions (thermal plants drop-outs)

- Random variation in wind power, hydro flows, etc. 
- Transmission constraints

The overall objective is efficiency, i.e. to supply the demanded electricity in a costminimising way.

During the hour of operation, the TSOs are responsible for security of supply and accommodate real-time deviations from ex ante energy schedules using balance power. The hourly imbalances for each BRP are considered as sales or purchases of balance power from their TSO. The net sale of balance power of a TSO is equal to its net purchases. The imbalance market operates for each settlement period of the trading day. TSOs have access to balance power in the form of frequency controlled reserves within seconds, fast reserves within 15 minutes and peak load reserves within hours. The terminology varies somewhat between the countries, and here we will follow Nordel's terminology and distinguish between frequency-controlled reserves (primary regulation) and fast reserves (secondary regulation); see Nordel (2008a) and (2008b).

The frequency-controlled reserves allow the TSOs to meet random minute-to-minute variations in demand and supply. In Nordel, there are two kinds:

i) The frequency-controlled normal operation reserve with a total amount of $600 \mathrm{MW}$ at $50 \mathrm{~Hz}$ for the Nordic countries. It should be automatically activated with a regulation capacity of $6000 \mathrm{MW} / \mathrm{Hz}$ to keep the frequency between 49.9 and $50.1 \mathrm{~Hz}$.

ii) The frequency-controlled disturbance reserve is normally about $1000 \mathrm{MW}$. This is activated at larger disturbances with frequency deviations down to $49.5 \mathrm{~Hz}$.

The so-called fast reserves (secondary regulation) are activated manually and used to restore the automatic reserve within 15 minutes. There are two categories of fast reserves:

i) Regulating bids: Reserves made available by regulating bids to the TSOs for upward or downward regulation. (In thermal systems these are usually called spinning reserves.) The TSOs submit all their country-specific bids to a common Nordic regulation list available in the common Nordic Operational Information System, NOIS. This market is labelled the Regulating Power Market, RPM. It is a singlebuyer market with single (marginal) prices for upward and downward regulation respectively. Objects with faster activation times (5 or 10 minutes) are earmarked in the bid list for use in emergency cases. 
ii) Fast disturbance reserves: Reserves also used to restore the automatic reserves. (In thermal systems these are usually called non-spinning reserves.) These are available in addition to the regulating bids and have different compositions in different countries. In Sweden and Finland, they consist of gas-turbines, which are owned or leased by the TSOs. In Norway, there is a specific weekly market, RKOM, to secure sufficient reserves in the system. In Denmark there are also daily markets based on tenders for reserves. These reserves are usually withheld until all regulating bids are utilised. Moreover, these are generally more expensive than the regulating bids.

The peak-load reserves (sometimes called tertiary regulation) are temporary peak reserves handled by the TSOs (Finland and Sweden). Since they may take several hours to activate, they are supposed to be used in more long-lasting peak-load cases. These reserves consist of thermal power plants (about $600 \mathrm{MW}$ ) in Finland and of thermal power plants but also industrial load reductions (in total up to 2000 MW) in Sweden.

An important feature of a spinning reserve is its ramp rate, i.e. the rate of change in its capacity utilisation. A typical ramp rate for a non-nuclear thermal power plant is $1 \%$ of its maximum operating rate per minute; hence at most $10 \%$ of its capacity can be available within 10 minutes. The ramp rate for hydro units is much faster. In fact, a hydro unit may reach full capacity within seconds, if not constrained by legal restraints on water flows.

The design of reserve markets and the role of the TSO vary significantly across power markets, and there is a multitude of potential designs from centralised dispatch to more decentralised market-oriented design and from energy remuneration to capacity remuneration.

In principle we may distinguish between two different models for power reserves, the energyonly model and the capacity model. In the stylised energy-only model generators are not compensated for keeping a certain amount of capacity available for peak-load periods. Instead the incentive is periods of very high spot and reserve market prices. Thus there is no or relatively high price cap or price regulation in this model. Although with some deviations, Nord Pool comes close to this model. There is, for example, a price cap, but at a very high level, €5000/MWh. There are also, however, some peaking reserves paid for by the TSOs as available capacity. 
Recently Sweden has taken an important step towards a more refined energy-only model. According to the proposal from the government, the Swedish TSO must gradually phase out the peak-load reserve contracts (2000 MW) during the period 2011 to 2020; see Prop (2009/10a).

In the stylised capacity model, there is an energy price cap, but generators are directly compensated for installed or available capacity. A typical example of this model is the old English-Wales Pool with a specific capacity component in the pool pricing formula (the probability of lost load times the value of lost load). Several electricity markets in the US also provide payments for available capacity; see Bushnell (2010).

\subsection{The value of regulating power}

Market power and strategic behaviour is a typical feature of most power markets. The repetitive nature of power auctions also facilitates tacit collusion and strategic behaviour. While spot market outcomes are investigated to a large extent, much less is known about markets for ancillary services. One exception is the California electricity market and especially during the crisis of 2000 and 2001. Knittel and Metaxoglou (2008) found indications of substantial market power in the California reserves market during the crisis. One reason behind this was a highly concentrated reserves market, and another reason was the design of the reserves market.

When we discuss the value of ancillary services here, we apply a perfect competition perspective, i.e. we discuss the value from the society's point of view and do not include price-cost mark-ups caused by market power, although market power may be a serious problem in auctions for procurement of ancillary services.

A generator has two options: to bid into the energy market or into the reserve market. In general, the true economic costs of reserve provision consist of a standby cost and/or an opportunity cost of not producing energy. For an on-line thermal unit running at minimum level, there is a fixed cost of being on-line and an efficiency penalty for not producing at high capacity and there may also be restrictions on the rate of change of output. Off-line units do 
not face any fixed economic costs and nor does interruptible load. On the other hand, there is a start-up cost for thermal units.

For a hydropower unit with storage capacity, technical restrictions are of relatively little importance. Yet, there are a number of constraints or legal restrictions that may affect the opportunity costs of providing reserves:

- Restrictions on minimum and maximum water levels

- Restrictions on maximum water level as a function of current water flows

- Restrictions on the rate of change in water flows through the turbines

- Restrictions on the ramp rate, i.e. the rate of change in water flows after a start-up of a turbine

- Restrictions on the maximum and minimum water flow through the turbines

- Restrictions on the water flow from one hydro plant to another in a river system and externalities caused by imperfect coordination between the power plants. The 'water flow distance' between plants is up to two days.

On the technical side, the two most important features are:

- That the efficiency varies with the rate of capacity utilisation in a rather complicated unit-specific way, with very low efficiency at low water flows, and, generally, the highest ratio of energy output and water flow is obtained at about $75 \%$ of capacity utilisation.

- That wear and tear is a function of the number of start-ups and stops.

Moreover, in the case of hydro, the opportunity cost of providing reserves also depends on expected reserve prices and energy prices in future periods.

However, there are two caveats. One is the importance of the hierarchical substitutability of reserves, and the other is congestion management. Hierarchical substitutability is a kind of service-quality differentiation. Automatic reserves can be used instead of, and have a higher value than, fast reserves, which in turn can replace, and has a higher value than, slower reserves. In a system dominated by hydropower with substantial storage capacity, the importance of this hierarchy is not very important. Congestion management is important in Nordel and requires so-called special regulation with bid-picking from the common Nordic list, which deviates from unconstrained merit order. 
Let us consider a generator with the opportunity to choose between bidding its supply into the spot market or into the regulation market. Automatic reserves and the fast reserves services can only be provided by on-line units. Thus, reserve services and energy production are joint services. You cannot provide one without the other. The decision to provide reserve services can therefore not be isolated from the decision to produce energy. A generator that produces reserves must forgo the profit from producing energy from the reserve portion of the capacity of that on-line unit. Thus, the cost or value of providing reserves is the opportunity cost of not providing energy. If, for example, a generator has a variable cost of producing energy of $€ 15 / \mathrm{MWh}$ and the spot market price is $€ 35 / \mathrm{MWh}$, then the generator has an opportunity cost of providing reserve services of $€ 20 / \mathrm{MWh}$. This is the profit forgone for the generator if he sells reserves, since he would attain a profit of $€ 20 / \mathrm{MWh}$ by selling into the energy market. The generator would not accept a price less than €20/MWh for providing reserves. Below that price, the generator will only provide energy and above that price he will prefer supplying reserve services. If arbitrage between markets works efficiently, the price for reserves should equal the cost of the marginal supplier in the energy market, when both markets are competitive, i.e. in the absence of market power.

The allocation of a certain amount of energy, E, between the spot market and the reserves market is equivalent with an optimal portfolio problem in finance, where a certain investment is allocated between different assets as in a Capital Asset Pricing Model (CAPM). Restrictions on production or water reservoir levels affect the total amount of energy, E, that can be allocated between the spot market and the reserves market but does not affect the relationships between spot and the expected reserves price. Thus with risk neutral agents and no market power (and zero discounting), the spot market price is the best prediction of the regulation price. ${ }^{2}$ This implies that the existence of market power in the regulation market can be tested for by investigating the difference between spot prices and regulation prices.

\footnotetext{
${ }^{2}$ We thank Thomas Tangeras for pointing this out in an ongoing work .
} 


\subsection{The impact of wind power}

The impact on reserve prices of a future increase in the supply of renewable energy with random supply, and especially wind power capacity, has become a topical issue in Scandinavia. There seems to be a wide-spread opinion that increase in wind-power generation will lead to increased demand for regulating power, much higher prices for reserves and a much higher value of regulated hydro power. We will address this issue here and discuss the future value of regulated hydro power during a period of rapid expansion of wind power generation. Our framework is a power system with substantial amounts of regulated hydro power that can either be supplied to the spot market or the regulating power market.

Let us start with some reflections on the nature of intermittent renewable technologies like wind and solar PV power in relation to the power system:

1. From a system-cost perspective these technologies cause increasing system costs similar to load fluctuations caused by end-use demand. From a policy perspective, however, there is one fundamental difference, intermittent power volatility is caused by nature, while end-use volatility may be sensitive to market design. Thus, the policy efforts in many countries to enhance end-use flexibility (for example by spot pricing or more load-following prices) to decrease price voltility will be counteracted.

2. A large share of intermittent renewable technologies will probably generate a steeper load-duration curve, the exact profile depending on the correlation between renewable generation and end-use demand. Because the steeper load-duration profile is caused by nature, the implication of this is that the close link between high end-use demand and high electricity prices no longer holds in a system with a large share of intermittent renewable technologies. Electricity price volatility will then be closely linked to random variation in wind speed and sun shine in addition to fluctuations in end-use demand.

3. The disconnection between end-use demand and prices in combination with high price volatility provide strong incentives for counteracting measures such as expansion of 
transmission capacity, investment in storage facilities and demand-side management; for an analysis and overview of previous research, se Chang et al (2010).

4. Because of their intermittent nature with random supply, the value of intermittent technologies as peak capacity is small. In general, it seems that $1 \mathrm{MW}$ of additional wind power capacity adds only 0.1-0.2 to peaking capacity; see for example Bushnell (2010) and Soder (2010).

5. From a technical point of view, there seems to be sufficient regulation capacity in Nord Pool for large amounts of wind power without new investments in new hydro or new thermal reserve capacity; see Soder (2010).

6. Because wind power expansion is driven by subsidies and not by consumer demand, there is an important supply effect as well as a demand-for-reserves effect on electricity prices. While the latter effect tends to increase electricity prices, the supply effect tends to decrease electricity prices.

7. A large share of intermittent renewable technologies will also change the optimal investment path and generation technology composition of power systems towards less base-load and more peaking capacity; see Bushnell (2010) for an analysis.

As discussed in Section 2.2 and 3.2, there is a close link through arbitrage between spot prices and regulation prices. An increase in wind power increases spot price volatility and consequently also increases volatility of regulation prices. Moreover, ceteris paribus, higher price volatility will increase demand for regulation and therefore tend to increase both spot prices and regulation prices.

However, a slow increase in electricity demand but rapid increases in wind power (or other power) generation would lead to a decrease in the spot market and regulation market electricity prices. The implication is that a rapid increase in wind power generation capacity may in fact decrease the value of reserve capacity. This has nothing to do with wind power per se, but occurs when demand dose not catch up with increasing supply. On the other hand, the random variation in wind power increases the demand for reserves during peaks and 
troughs, to some extent offsetting the downward price push from the increase in electricity supply. The net outcome may very well be a decrease in spot prices and consequently in regulation prices. As shown in Figure 6, West-Denmark had the largest spot price volatility but also the lowest average price, 2001-February 2010.

As regards Sweden, in addition to the renewed target in the green electricity certificate system of an increase in renewable electricity, from previously $17 \mathrm{TWh}$, to $25 \mathrm{TWh}$ between 2002 and 2020, there is also a specific "national planning framework" for year 2020 of 20 TWh on-shore and 10 TWh off-shore wind power; see Prop (2009/10b).

An addition of 30 TWh Swedish wind power in the Nordic system would, ceteris paribus, reduce the electricity price by $15-20$ percent if we assume price elasticity in the range of 0.3 0.5. When Sweden is an isolated price area the impact will be much larger, a price decrease by 40-60 percent. Thus, the balance between increases in supply and changes in demand is very important for the future value of hydro power.

The impact of hydro power on regulation prices in Sweden depends also on the location of new wind power relative to transmission constraints; hence the location of new wind power is important for the demand for reserves. This can be illustrated by the spot price volatility in the six Norwegian spot price areas (which were reduced to five, March 15, 2010); see Figure 7. The sequence in Figure 7 is from most volatile to least volatile price area.

The time period in Figure 7 varies from 2001 to February 2010 for Oslo, from 2002 for Bergen, Trondheim and Tromso, from 2006 for Kristiansand and from 2008 for Kristiansund. The average volatility of the pair-wise hourly values in Nord Pool is shown in Table 1.

In Nord Pool there is one low-volatility group consisting of Bergen, Kristiansand and Oslo, one mid-volatility group consisting of Tromso, Trondheim,Sweden and Finland and one high-volatility group consisting of Kristiansund, East-Denmark and West-Denmark. Bergen, Kristiansand and Oslo are all located in hydro-rich areas. East-Denmark and West-Denmark have a high share of wind power, while Kristiansund is located in Mid-Norway with rather weak interconnections with other areas. 


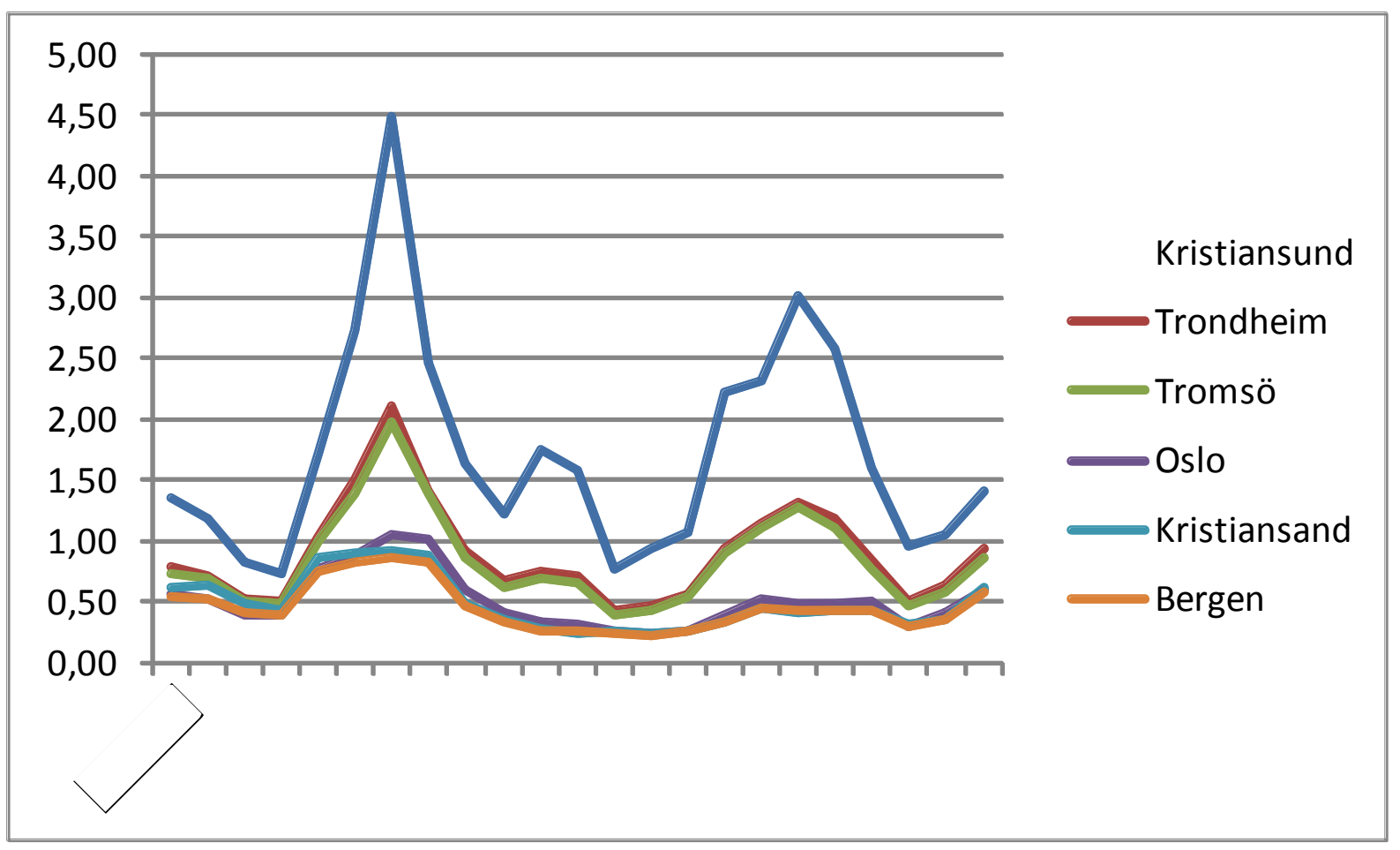

Figure 7. Spot price volatility measured as standard deviation for consecutive hours during the day.

\begin{tabular}{|l|l|}
\hline Spot price area & Volatility \\
\hline Bergen & 0.46 \\
\hline Kristiansand & 0.49 \\
\hline Oslo & 0.51 \\
\hline Tromso & 0.85 \\
\hline Trondheim & 0.90 \\
\hline Sweden & 1.09 \\
\hline Finland & 1.25 \\
\hline Kristiansund & 1.72 \\
\hline East-denmark & 1.97 \\
\hline West-Denmark & 2.10 \\
\hline
\end{tabular}

Table 1. Spot price volatility measured as standard deviation for consecutive hours during the day. 
In the Swedish transmission system, $85 \%$ of the hydro capacity is located north of the socalled 'snitt 2' (bottleneck 2) in the north. In general, the main reserve demand problem in all parts of Sweden, except in the South, seems to be capacity for downward regulation during strong-wind periods. Water spilling may increase due to lack of downward regulation capacity during periods of ample supply of hydro and wind. This will be the case with a large expansion of wind power in the north of Sweden, which is the main conclusion in Amelin et al. (2009). In the south, there may also be an upward regulation problem due to transmission bottlenecks. On the other hand, an expansion in the south will reduce the demand for 'normal' transmission capacity from the north; see Gustafsson and Neimane (2009).

If a large capacity of wind power is located in a surplus area with transmission constraints, priority for wind generation will result in spilling of water, decreasing the opportunity cost of reserves to zero. A large capacity of wind power in the north of Sweden will increase the number of hours that potential electricity supply exceeds transmission constraints. It may then be impossible to regulate down hydro without spilling water. This seems to be very likely especially during January and February; see Amelin et al. (2009). Amelin et al. (2009) also show the importance of reliable forecasting of wind energy output and Gustafsson and Neimane (2009) the importance of the incentives for the market agents to provide good forecasts.

However, if the proposal to divide the Swedish electricity market into four price areas (in 2011) is realised, the excess supply problem may be changed or somewhat reduced although it may not be eliminated. Four price areas within Sweden would increase area price volatility and there will be long-run price differences between the areas. Both these components will provide incentives of the types discussed above for investments in demand side management and storage facilities in addition to increases in transmission capacity. From an economic point of view this would be a more efficient way to handle the excess supply problem.

Another step in the efficiency-enhancing direction is the introduction of negative spot market prices instead of curtailing load. This seems to be common in spot markets with a large wind power capacity with examples from South Australia, Texas, etc. of extended periods of frequently negative spot prices. Within the Nord Pool area, Denmark has a large wind power capacity and with high wind feed in Denmark, especially western Denmark there have been 
hours where sales bids have been curtailed at price zero. Curtailment of supply may yield an imbalance cost for the affected supplier and thus create a willingness to pay to supply power to the market Negative spot prices should provide a strong incentive for voluntary downward regulation and should lead to decreased demand for regulating power.

From November 30, 2009, a Nord Pool price area may have negative spot prices with a price floor of minus €200/MWh. During the night between December 25 and 26, 2009, the WestDenmark had eight consecutive hours of negative spot prices, down to minus $€ 119.9 / \mathrm{MWh}$ during four hours. West-Denmark got a slightly negative spot price also in the morning of December 20. If we add the hours of zero spot market prices with the hours of negative prices in West-Denmark, we should have experienced negative prices 101 hours (31 days) in 2009. The most extreme day had zero prices during 11 hours.

However, in addition to the expansion of wind power, there are a large number of other factors that will affect the future price level of electricity within Nord Pool, for example:

- Expansion of export/import transmission capacity

- New investments in non-renewable electricity generation like nuclear, hydro and natural gas electricity production

- Closing-down of electricity intensive industries

- Successful energy conservation programs incentivised by the EU energy efficiency target

- The development of smart grid solutions making end-use demand much more flexible in real time

Except for the first factor, which, of course, is important, the other four point in the direction of non-increasing future electricity prices. All together, it seems that the opportunity cost of providing reserves may decrease somewhat with a rapid expansion of wind power in Scandinavia although the extent of this decrease will depend on several other factors.

In the long run the available regulated hydro power capacity may be absorbed as reserves for regulation of intermittent renewable technologies. Then the opportunity costs of alternative regulation possibilities, such as thermal peaking plants and storage facilities, will determine 
the value of regulated hydro power. At that time, but not until then, would we expect much higher values of regulated hydro power.

\section{Conclusions}

The social value of a reservoir for a hydropower plant depends on the optimal prices of electricity. In order to study the value of reservoirs for both seasonal regulation and for realtime balancing regulation, an important question is whether the spot market and balancing markets are giving the correct price signals. However, this is beyond the issues studied here, and we refer to spot-market prices and balancing market prices as giving the value of a reservoir. The seasonal regulation of hydropower, nuclear and thermal power in addition to wind power is analysed using a dynamic model to solve a social management problem. The necessary condition for maximising consumer plus producer surplus is used to study qualitative features of optimal electricity prices within a planning horizon. We use figures extensively to make the discussion of implications of optimal solutions accessible. The impact of greater wind power capacity is greater price volatility, while the impact on the average price level is ambiguous, depending on the balance between increase in supply and demand. Since the expansion of wind power is not derived from consumers' willingness-topay, increased wind capacity may easily lead to more production than matched by the increase in demand over time. Unless export possibilities out of Nord Pool are expanded by investing in interconnectors to continental Europe or England, this will lead to a lower average price, and the average value of hydropower will consequently fall.

Yet, the value of hydropower may not necessarily go down, since wind availability may be so abundant in some periods that no water will be used at all, thus facilitating transfer of even more water to high-price periods.

These conclusions were established in a model assuming full certainty. Discussing the implications of uncertainty of both wind resource and inflows to reservoirs is a formidable exercise if based on a formal model. We offered some conjectures implying that uncertainty will amplify the price volatility. The situation prevailing when reservoirs are fairly run down is of special concern. Then it may be necessary to consider a market for hydro reserves to 
cover the event of disappearance of wind in a high-demand period. The need for more power capacity of hydro stations may also increase, and such investments must also be made economically attractive to be realised in a market.

The need for a balancing market in real time arises because it is hardly practical to set up a complete market in real time. Wholesale markets are settled on average 24 hours ahead, and there may then be a discrepancy between predictions and outcomes both for supply and demand. In order to keep the electricity flowing to the desired physical specifications, action must be taken to secure balance in real time.

The key to understanding the value of regulating power in a power market is the arbitrage opportunities between the spot market and the regulation market. When arbitrage works, the main conclusions are that:

1. Energy prices and ancillary prices should move in parallel

2. The best forecast of regulation prices is spot-market prices.

The impact on reserve prices of a future increase in the supply of renewable energy with random supply, and especially wind power capacity in Scandinavia, is thus basically a question about the future spot prices. Considering a number of factors on the electricity demand and supply side there seems to be strong reason to challenge the wide-spread opinion that increase in wind-power generation will lead to much higher prices for reserves and a much higher value of regulated hydro power.

A slow increase in electricity demand and a rapid increase in wind power generation should lead to a decrease in the spot market electricity price. The larger volatility in electricity supply and spot market prices caused by increased wind energy should lead to more volatile prices of regulating power, but the average price for balancing power might decrease. 


\section{References}

Amelin, M., Englund, C. and Fagerberg, A. (2009). ”Balansering av vindkraft och vattenkraft i norra Sverige.” Elforsk rapport 09:88.

Amundsen, E.S. and Bergman, L. (2008). ”Provision of operating reserve capacity: Principles and practices on the Nordic Electricity Market.” MPRA paper No 10861.

Bellman, R. (1957). “Dynamic Programming.” Princeton University Press.

Bushnell, J. (2010), “Building Blocks; Investment in Renewable and Non-Renewable Technologies.” Energy Institute at Haas, Wp 202.

Chang, J., Spees, K. and Weiss, J. (2010). Renewables and Storage - Does Size Matter? Unpublished, The Brattle Group.

Chao, H.P. and Wilson, R. (2002). "Multi-Dimensional Procurement Auctions for Power Reserves: Robust Incentive-Compatible Scoring and Settlements Rules.” Journal of Regulatory Economics, 22(2), pp 161-183.

Førsund, F. R. (2007). Hydropower Economics. New York: Springer Science+Business Media.

Førsund, F. R. (2009). “Energy in a Bathtub: Electricity trade between countries with different generation technologies.” Memorandum No 17/2009, Department of Economics, University of Oslo

Gustafsson, K. and Neimane, V. (2009). “Stora volymer vindkraft.” Elforsk rapport 09:103

Hveding, V. (1968). “Digital simulation techniques in power system planning.” Economics of Planning 8(2), 118-139. 
IEA Wind Task 25 (2009). "Design and operation of power systems with large amounts of wind power”, Final report, Phase one 2006-08, http://www.ieawind.org/AnnexXXV.html

Knittel, C.R. and Metaxoglou, K. (2008). “Diagnosing Unilateral Market Power in Electricity Reserves Market.” Department of Economics, University of California, Davis, 2008.

Nordel (2008a).’Description of Balance Regulation in the Nordic Countries.”31.03.

Nordel (2008b). “Harmonisation of Balance Regulation in the Nordic Countries.” 12.12.

Prop (2009/10a). “Effektreserven i framtiden.” Regeringens proposition 113.

Prop (2009/10b). ”Höjt mål och vidareutveckling av elcertifikatsystemet.” Regeringens proposition 133.

Soder, L. (2010). “Possibilities for Balancing Wind Power Variations”, Electric Power Systems, KTH, February 8. 


\section{Appendix}

\section{Model for management of electricity generation based on different technologies}

\section{Assumptions}

Types of generation technologies:

iv) Hydro, $e_{t}^{H}$

v) Two types thermal; nuclear, $e_{t}^{N}$, and conventional thermal, $e_{t}^{C}$

vi) Wind and run-of-the-river added together as intermittent electricity generation, $e_{t}^{I}$

vii) There is full certainty about the intermittent production profile, the inflow to the reservoirs and the period demand functions.

The generation is viewed as one system for each of the technologies.

Hydro and intermittent generation have zero current cost that depends on the output; all current costs are fixed costs that depend on non-negative production. The fixed costs are neglected in the analysis since we are not looking at new investments but only at the problem of optimal management of existing capacities. Individual hydro plants and storage capacities $\bar{R}$ are added together, according to Hveding’s conjecture (Hveding, 1968; Førsund, 2007).

Thermal generations have current primary fuel costs that depend on the output levels $c^{C}\left(e_{t}^{C}\right), c^{N}\left(e_{t}^{N}\right)$. The fixed cost part is not included in the cost functions. The cost functions are constructed as merit-order functions. It is assumed that we have unique rankings (Førsund, 2007). The outputs of the thermal sectors are constrained to $\leq \bar{e}^{C}, \bar{e}^{N}$.

The social planner maximises consumer plus producer surplus using demand functions for electricity for each period, $p_{t}\left(x_{t}\right)$, written on price form, where $x_{t}$ is the total demand, and the cost functions. The social planning problem is to maximise the objective function:

$$
\max \sum_{t=1}^{T}\left[\int_{z=0}^{x_{t}} p_{t}(z) d z-c^{C}\left(e_{t}^{C}\right)-c^{N}\left(e_{t}^{N}\right)\right]
$$


subject to the constraints

$X_{t}=e_{t}^{H}+e_{t}^{C}+e_{t}^{N}+e_{t}^{I}$

$R_{t} \leq R_{t-1}+w_{t}-e_{t}^{H}$

$R_{t} \leq \bar{R}$

$e_{t}^{C} \leq \bar{e}^{C}$

$e_{t}^{N} \leq \bar{e}^{N}$

$e_{t}^{I} \leq \bar{e}^{I}$

$x_{t}, e_{t}^{H}, e_{t}^{C}, e_{t}^{N} \geq 0, t=1, . ., T$

$T, R_{o}, \bar{R}, \bar{e}^{C}, \bar{e}^{N}, \bar{e}^{I}$ given, $R_{T}$ free

We only include a constraint on the size of the water reservoir, but not on production or power constraints. Environmentally-based constraints on water flows and on ramping up and down over periods when the time resolution is detailed enough to make such constraints meaningful may also be introduced (Førsund, 2007).

The Lagrangian is:

$$
\begin{aligned}
& L=\sum_{t=1}^{T}\left[\int_{t=0}^{e_{t}^{H}+e_{t}^{C}+e_{t}^{N}+e_{t}^{I}} p_{t}(z) d z-C^{C}\left(e_{t}^{C}\right)-c^{N}\left(e_{t}^{N}\right)\right] \\
& -\sum_{t=1}^{T} \theta_{t}^{C}\left(e_{t}^{C}-\bar{e}^{C}\right) \\
& -\sum_{t=1}^{T} \theta_{t}^{N}\left(e_{t}^{N}-\bar{e}^{N}\right) \\
& -\sum_{t=1}^{T} \lambda_{t}\left(R_{t}-R_{t-1}-w_{t}+e_{t}^{H}\right) \\
& -\sum_{t=1}^{T} \gamma_{t}\left(R_{t}-\bar{R}\right)
\end{aligned}
$$

Intermittent generation is not subject to optimisation, but is assumed to be utilised within the feasible capacity.

Necessary first-order conditions are: 


$$
\begin{aligned}
\frac{\partial L}{\partial e_{t}^{H}} & =p_{t}\left(e_{t}^{H}+e_{t}^{C}+e_{t}^{N}+e_{t}^{I}\right)-\lambda_{t} \leq 0\left(=0 \text { for } e_{t}^{H}>0\right) \\
\frac{\partial L}{\partial e_{t}^{C}} & =p_{t}\left(e_{t}^{H}+e_{t}^{C}+e_{t}^{N}+e_{t}^{I}\right)-C^{C^{\prime}}\left(e_{t}^{C}\right)-\theta_{t}^{C} \leq 0\left(=0 \text { for } e_{t}^{C}>0\right) \\
\frac{\partial L}{\partial e_{t}^{C}} & =p_{t}\left(e_{t}^{H}+e_{t}^{C}+e_{t}^{N}+e_{t}^{I}\right)-C^{N^{\prime}}\left(e_{t}^{N}\right)-\theta_{t}^{N} \leq 0\left(=0 \text { for } e_{t}^{N}>0\right) \\
\frac{\partial L}{\partial R_{t}} & =-\lambda_{t}+\lambda_{t+1}-\gamma_{t} \leq 0\left(=0 \text { for } R_{t}>0\right) \\
\lambda_{t} & \geq 0\left(=0 \text { fo } r R_{t}<R_{t-1}+w_{t}-e_{t}^{H}\right) \\
\gamma_{t} & \geq 0\left(=0 \text { fo r } R_{t}<\bar{R}\right) \\
\theta_{t}^{C} & \geq 0\left(=0 \text { fo } e_{t}^{C}<\bar{e}^{C}\right) \\
\theta_{t}^{N} & \geq 0\left(=0 \text { for } e_{t}^{N}<\bar{e}^{N}\right), \quad t=1, . ., T
\end{aligned}
$$

Intermittent energy is assumed to be used when available to zero production-dependent cost. Thus, intermittent energy will influence the solutions for how to use all the other types of technologies. It will be of special interest to discuss extreme periods when intermittent energy is zero and at the maximal level. It is straightforward to split intermittent energy into wind power and run-of-the-river hydro power.

The conditions for no use of each of the generating technologies in a period are:

Hydro power:

$$
p_{t}\left(e_{t}^{C}+e_{t}^{N}+e_{t}^{I}\right)-\lambda_{t} \leq 0
$$

If the shadow price on water (water value) is greater than the market price, then no water shall be used in this period. For this to be optimal, we must have that the reservoir is not constrained; we must have the shadow price on the reservoir constraint equal to zero. For positive inflow, we know that the reservoir level is then positive. This implies $-\lambda_{t}+\lambda_{t+1}=0$.

It will then be optimal to postpone the use of water to a later period when the market price becomes equal to the water value. We must assume that electricity is produced by at least one of the other technologies.

Conventional and nuclear thermal:

$$
\begin{aligned}
& p_{t}\left(e_{t}^{H}+e_{t}^{N}+e_{t}^{I}\right)-c^{C^{\prime}}\left(e_{t}^{C}\right) \leq 0 \\
& p_{t}\left(e_{t}^{H}+e_{t}^{C}+e_{t}^{I}\right)-c^{N^{\prime}}\left(e_{t}^{N}\right) \leq 0
\end{aligned}
$$


If no conventional or nuclear capacity is used, the shadow price on the corresponding capacity constraint is zero. We then have that the condition for not using a technology is that marginal cost at zero level of output is greater than the market price. We must assume that electricity is produced by at least one of the other technologies. It may be realistic to assume that the marginal cost of conventional thermal at zero production is higher than the maximal marginal cost of nuclear power:

$C^{C^{\prime}}(0) \geq c^{N^{\prime}}\left(\bar{e}^{N}\right)$.

This means that all the nuclear capacity will be utilised before conventional thermal is taken into use. (Although not modelled, ramping possibilities of nuclear stations are very limited, and the marginal cost of nuclear may alternatively be assumed to be constant, but differing according to vintage of the plant).

\section{Intermittent generation of electricity (wind and run-of-the-river hydro)}

Because of the zero production-dependent cost, intermittent energy will always be used, unless using it will cause disruption for the use of the other technologies that have higher costs than spilling the intermittent energy. This may for instance be realistic for regulating nuclear power. It may be more costly to reduce the level of generation and then ramp up again later than spilling the intermittent energy. We will discuss the extreme cases of zero intermittent energy and the maximal level. Reactions to variation between these levels will, more or less, follow from the discussion of the extreme cases.

In the case of zero level of intermittent energy, we see from the conditions in (A3a) that there will be consequences for the use of the other technologies. The typical case will be that at least one other technology will produce more electricity. In a situation where the thermal technologies are used and constrained, it must be hydro power that increases provided that enough water is available in the reservoir. When there is spare thermal capacity and because the cost of ramping up and ramping down thermal power is not modelled, it may seem more profitable to use thermal capacity to compensate for the absence of intermittent power than what it is in reality. The zero cost of ramping hydro power is quite realistic from a production-technical point of view, but there may be environmental costs of changing the levels of reservoirs and water flows downstream. We may take such factors into consideration by formulating restrictions on the amount of ramping within a period, as mentioned above. 
The case of full capacity utilisation of the thermal capacities may occur in a high-peak demand period, e.g. a winter week in January. If there is not enough available water in the reservoirs, production will be reduced and the price will be higher in this period. Even if there is enough water available, it may still be optimal to have a higher price, i.e. not to compensate the full loss of intermittent production, since there may be later periods when the intermittent production will be zero and there will be an even higher demand. Then it is better to store water for these periods. Remember that we have assumed full certainty about the availability of intermittent production, inflows of water to the reservoirs, and the demand functions.

In the case of maximal production of intermittent energy, a typical reaction is that production from other technologies will be reduced or even zero. For the latter case to occur, we have from (A4) and (A6) the following conditions:

$$
\begin{aligned}
& p_{t}\left(e_{t}^{I}\right)-\lambda_{t} \leq 0 \\
& p_{t}\left(e_{t}^{I}\right)-c^{C^{\prime}}(0) \leq 0 \\
& p_{t}\left(e_{t}^{I}\right)-c^{N^{\prime}}(0) \leq 0
\end{aligned}
$$

In addition, we must for hydro power have the condition that it is possible to store the total inflow of period $t$, i.e. $R_{t-1}+w_{t}<\bar{R}$. The price in the period is then determined as

$$
p_{t}=p_{t}\left(\bar{e}^{I}\right)
$$

Depending on the demand and supply of intermittent electricity, this price may be driven down to zero.

The general conclusion we may draw is that with intermittent power, it will be socially optimal to have a greater variation in the price than the case where the average level of the intermittent energy is available in every period. 